\title{
Fault Characteristics, Energy Estimates, and Earthquake Recurrence: What One Seismologist Wants from Fault Drilling
}

by Jim Mori

\author{
doi:10.2204/iodp.sd.s01.42.2007
}

There are some significant differences between the way seismologists and geologists typically look at faulting from large earthquakes. Seismologists tend to analyze waveform data which can usually resolve structures on the order of tens of kilometers; possibly down to one kilometers there is very good near-field data. Also, the derived physically properties are averaged over this scale length. Although it is difficult to resolve small scale features, seismologic studies have the advantage of seeing all depths of the fault. In contrast fault zone geologists can make direct observations of the fault zone structures and properties, which are quite different from the remote sensing techniques of seismologists. Geologists tend to look at structures on the scale of microns to meters when examining the cores obtained from drilling into faults. These observations are spot measurements and it is often difficult to assess how representative they are of the entire fault. Also, fault zone sample studies are usually limited to a few kilometers depth, which may barely be in the range of the seismogenic zone that produces the seismic waves. These differences mean that seismologists and geologists are often looking at quite different aspects of the earthquake process. The approaches are different, but can also be complementary.

\section{Drilling Depth}

The depth of drilling is an important point for fault zone investigations. To compare physical properties obtained in cores with seismological results obtained from waveform analyses, it is necessary to reach depths of the seismogenic zone, that is the regions of fault slip that have significant stress change to produce seismic waves. The shallow regions of faults, where materials have low rigidity, likely slip sympathetically with the seismogenic zone but do not produce seismic waves. The depth of the beginning seismogenic zone depends on local geology and probably is a transition zone. Waveform inversion studies suggest that the seismogenic zone may be as shallow as $1 \mathrm{~km}$ for the Chi-Chi, Taiwan earthquakes (Ji et al., 2001). It would be interesting if geologic studies could distinguish between seismic and nonseismic slip of the fault.

\section{Temperature Measurements}

One of the fundamental issues in understanding the physical mechanisms of earthquakes is clarifying the level of friction on the fault. One way to estimate the frictional levels during the faulting is to measure the heat produced. Measurements of the heat flow associated with the San Andreas fault have long been discussed over the past decades (e.g., summarized in Scholz, 2002, section 3.4.4). A more direct estimate would be to measure the fault zone temperatures immediately after a large earthquake. There were informal discussions to measure fault-zone temperatures following the large 1992 Landers and 2001 Denali earthquakes, although measurements were not done. Currently, the only available data of fault-zone temperatures following an earthquake are for the 1999 Chi-Chi, Taiwan earthquake (Kano et al., 2006). This result infers a very low level of dynamic friction during the earthquake; however, the measurement was made 5 years after the earthquake, when the temperature signal was quite small, and it is difficult to make clear interpretations. To obtain better estimates of the fault-zone heat, measurements more quickly (a few months) after a large earthquake are necessary (Fig.1).

\section{Asperities}

Fault slip during large earthquakes is usually heterogeneous with regions of large and small slip. The areas of large slip are often termed 'asperities'. These areas of large slip dominate the energy radiation and may control the rupture process. There are also suggestions that the stress accumulation during the interseismic period is different on the asperities, compared to the rest of the fault. The actual physical process that controls the stress accumulation and large slip of the asperities is currently an active topic of discussion in seismology. Yamanaka and Kikuchi (2004)

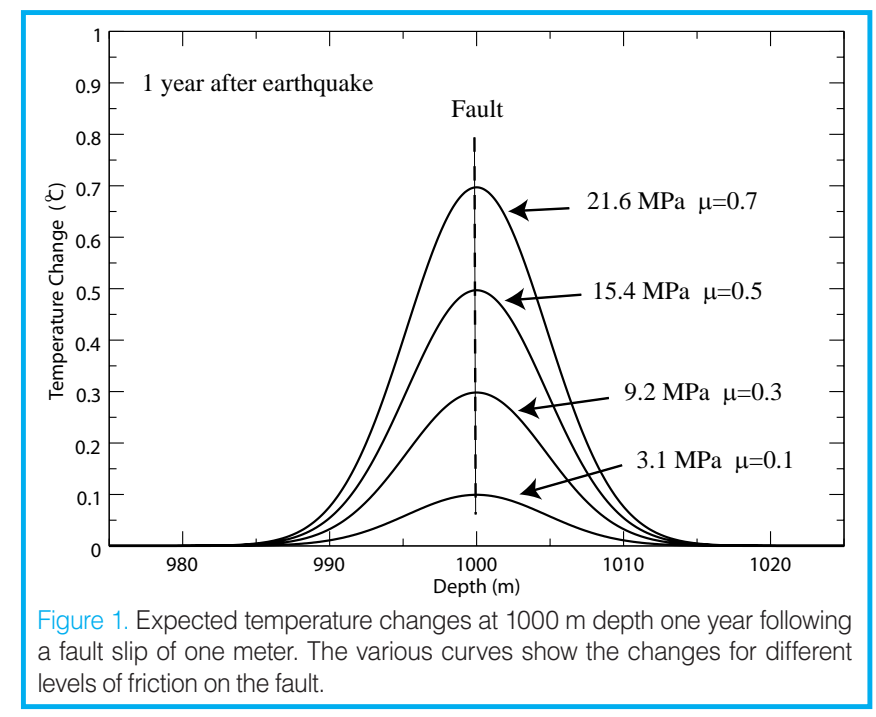


Table 1. Complementary differences between typical seismology studies and fault zone investigations.

\section{Seismological Observations-Macroscopic \\ Scales of $\mathrm{km}$ to tens of $\mathrm{km}$, average properties of the fault zone \\ Remote sensing of entire depth range of fault zone \\ Estimates of total seismic radiated energy \\ Estimates of non-radiated (fracture?) energy \\ Seismic determination of slip weakening distance}

suggest that asperities are persistent features that are characteristic of a fault zone. However, results from the two recent Parkfield earthquakes and also large subduction earthquakes along the New Britain trench (Park and Mori, 2007 ) indicate that asperity distributions can be different for repeated ruptures of the same zone. Some related seismological issues that might be answered by detailed analyses of fault zone structures from drilling include the following:

- Are repeating earthquakes on a fault occurring on the same exact fault plane?

- Are the locations of asperities (areas of large slip) the same in repeating earthquakes?

- What is the physical cause of asperities?

- How does each earthquake contribute to making the fault zone?

- What is the fracture/healing process on the fault?

\section{Macro- and Microscopic Observations}

Kanamori and Heaton (2002) emphasize the importance for understanding and integrating small and large scale results for fault zone studies. The physical processes that occur on microscopic scales of the fault zone are reflected in the macroscopic observations made by seismologists.

Table 1 lists some of the different and complementary aspects of seismological and borehole studies of earthquakes and fault zones. For example, detailed analyses of near-field seismograms for large earthquakes can give estimates of both the radiated and non-radiated energy. The non-radiated energy is thought to be dissipated by processes such as fracture formation and heat production. These dissipated processes can be studies with direct measurements of temperature, crack distributions, and grain sizes obtained from borehole observations.

\section{Onshore and Offshore Drilling}

The logistics of drilling crustal faults on land and drilling faults offshore, such as large megathrust subduction zones, are quite different and are addressed by the differences in the programs of the International Continental Scientific Drilling Program (ICDP) and the Integrated Ocean Drilling Program (IODP). Crustal onshore faults tend to be shallower and more accessible to drilling investigations. For large offshore subduction zones, identifying and reaching the fault surfaces with drilling is a difficult endeavor. Drilling both faulting environments is important for understanding the

\section{Fault Zone Investigations-Microscopic}

Scales of nanometers to meters for spot measurements

Direct samples from shallow depths of the fault

Estimates of heat generated by temp. measurements after earthquakes

Determination grain size, crack distributions for energy estimates

Estimates of fault frictional properties from core samples

physical structures of the fault zones. There are also opportunities for cooperative onshore/offshore drilling projects that can combine observations of the same fault zone.

\section{Wish List}

Finally, to address the issues mentioned above, I would recommend that a fault zone drilling program would include the following (roughly in order of difficulty).

- Design projects to combine microscopic and macroscopic observations

- Drill to sufficient depth to reach the seismogenic zone (region that produces seismic waves)

- Drill soon after a large earthquake to measure temperature changes caused by faulting

- Use deep boreholes for measurements of earthquakes and strain (borehole observatories)

- Sample a fault in the same place before and after an earthquake

\section{References}

Ji, C., Helmberger, D.V., Song, T.R., Ma, K.-F., and Wald, D.J, 2001. Slip distribution and tectonic implication of the 1999 ChiChi, Taiwan, earthquake. Geophys. Res. Lett. 28:4379-4382, doi:10.1029/2001GL013225.

Kanamori, H. and Heaton, T.H., 2002. Microscopic and macroscopic physics of earthquakes. In Rundle, J., Turcotte, D.L., and Klein, W. (Eds.), Geocomplexity and the Physics of Earthquakes, Geophysical Monograph no. 120, Washington, DC (American Gephysical Union), 147p.

Kano, Y., Mori, J. Fujio, R., Ito, H., Yanagidani, T., Nakao, S., and Ma, K.F., 2006. Heat signature on the Chelungpu fault associated with the 1999 Chi-Chi, Taiwan earthquake. Geophys. Res. Lett., doi:10.1029/2006GL026733.

Park, S. and Mori, J., 2007. Are asperity patterns persistent? Implication from large earthquakes in Papua, New Guinea, J. Geophys. Res., doi:10.1029/2006JB004481.

Scholz, C.H., 2002. The Mechanics of Earthquakes and Faulting. Cambridge (Cambridge University Press), $471 \mathrm{p}$.

Yamanaka, Y. and Kikuchi, M., 2004. Asperity map along the subduction zone in northeastern Japan inferred from regional seismic data. J. Geophys. Res., 109, B07307, doi:10.1029/2003JB002683.

\section{Author}

Jim Mori, Disaster Prevention Research Institute, Kyoto University, Gokasho, Uji, Kyoto, 611-0011, Japan, e-mail: mori@eqh.dpri.kyoto-u.ac.jp. 